\title{
ROMPENDO O EPISTEMICÍDIO: conhecimento em Raça e Cultura e a produção do GT 21 da ANPEd
}

\author{
Lucimar Rosa Dias \\ Mailsa Carla Pinto Passos \\ Tatiane Cosentino Rodrigues
}

Da nossa memória, fabulamos nós mesmos (Adirley Queirós)

Esta Seção Temática da Revista Teias, intitulada Raça e Cultura, consiste em um marco de comemoração, mas também em uma iniciativa de resistência e de afirmação do propósito de um coletivo. Pesquisadoras e pesquisadores que se debruçam desde há muito sobre a produção de conhecimento que tematiza questões étnico-raciais no Brasil e educação, participantes do Grupo de Trabalho 21 (GT 21 Educação e Relações étnico-raciais) da Associação Nacional de PósGraduação e Pesquisa em Educação (ANPEd), com trajetórias de luta na afirmação da centralidade desses estudos em uma sociedade como a nossa, em que o racismo estrutural é a massa que "dá liga" e amalgama-se nos alicerces e nas paredes da sociedade brasileira. O racismo é também emboço sobre o qual o constructo da colonialidade passou tinta fina, na tentativa de disfarçá-lo pelo discurso falseado da democracia racial.

Uma das bases dessa democracia discursiva é o epistemicídio (CARNEIRO, FISCHMANN, 2005), uma das manifestações do racismo estrutural, dentre outras tantas, que se expressa pelo apagamento dos saberes dos povos originários e afro-diaspóricos. Por isso, uma das tarefas de dossiês como esse é a de colocar à disposição da comunidade científica a produção de pesquisadores e pesquisadoras que, em muitos casos, se utilizam de bibliografias, conceitos e objetos de pesquisa vinculados ao campo das relações étnico-raciais, na perspectiva da ruptura com a desvalorização e por vezes negação das contribuições científicas nas diferentes áreas de conhecimento, vindas de terras africanas no passado e no presente.

As pesquisas que se debruçam sobre essas questões - e outras afins - têm o caráter de reparação histórica com esses grupos, e o objetivo de problematizar diferentes formas pelas quais "[...] conhecimento e poder racial se entrelaçam" (KILOMBA, 2019, p. 49). Mais ainda, como também lembra a mesma autora, "[...] criar novos papéis fora dessa ordem colonial" (KILOMBA, 2019 p. 69). Esse conjunto de pesquisadoras e pesquisadores realizam a tarefa inadiável de arrancar as máscaras do conhecimento produzido sob a orientação da supremacia branca, infelizmente tão comum ainda em muitos ambientes acadêmicos assumindo, assim, a tarefa de reinventar uma outra ordem.

Se existem teorias sociais que nos impõem concepções heteronormativas e eurocentradas, nosso papel como produtoras e produtores de conhecimento é nos contrapormos a esses discursos com nossos corpos, nossas vozes, nossas maneiras de fazer ciência, nossos saberes, não como experiência exótica e bissexta, mas como conhecimentos legítimos e urgentes. Nossas histórias e descobertas as contamos nós mesmas / nós mesmos, parafraseando a epígrafe desse texto.

O GT 21 da ANPEd é um desses espaços em que nos encontramos para "retirar as máscaras brancas" do conhecimento, para nos aquilombarmos. Aquilombados e livres das 
máscaras com as quais tentaram nos amordaçar / silenciar, nos invisibilizar, trabalhamos pela descolonização epistêmica, o que significa pensar e sentir em diálogo com uma produção científica multidisciplinar e emancipatória, que torna o ato de fazer ciência democrático e justo. Nosso quilombo simbólico dá visibilidade, no campo da produção acadêmica, àquelas e àqueles a quem os pressupostos da colonialidade do saber (QUIJANO, 2005) quis incutir um discurso de incapazes de produzir conhecimento — percepção que se desconstrói a cada artigo desse número de Teias.

O volume reúne, então, artigos sobre Raça e Cultura, que marcam os 20 anos do Grupo de Trabalho Educação e Relações étnico-raciais. Um projeto acalentado desde 2018. Comemoramos o período em que esse conjunto de pesquisadoras e pesquisadores comprometidos com a educação antirracista fincou sua bandeira de luta no espaço já consagrado por compartilhar conhecimento na área de educação. Nesse espaço de tempo construiu-se e trabalhou-se para legitimar um fórum de debate acadêmico e a formação científica de jovens estudantes da pós-graduação. Fundado na ANPEd, primeiramente como Grupo de Estudo (GE), depois de dois anos se consolida como Grupo de Trabalho, nos termos regimentais da Associação. Foi-se, então, formalizando um lugar para apresentação e discussão de questões fundamentais para a educação brasileira: a educação para relações étnico-raciais.

Desde então, a trajetória do GT 21, de suas pesquisadoras e pesquisadores, tem sido tanto a da consolidação de estudos e pesquisas com a temática quanto o investimento no avanço dessas pesquisas no campo da educação antirracista e a sedimentação das relações étnico-raciais como área de produção do conhecimento, com campos teórico e metodológico próprios.

Ao acompanharmos a história do GT 21 e de trabalharmos na organização desse dossiê, temos que ressaltar que, mesmo no contexto atual, extremamente difícil para pesquisas em ciências humanas e sociais, é impossível admitir um passo atrás na trajetória de nossa luta em direção à educação antirracista. Há, nas diferentes instituições de ensino e pesquisa por todo o país, um importante acúmulo de conhecimentos que será constatado nos artigos que se seguem.

Abre-se a seção temática com o artigo Mulheres quilombolas na comunidade do Córrego do Meio e a busca pela educaşão formal, que apresenta uma pesquisa de mestrado que versa sobre experiências de mulheres quilombolas em espaços de educação formal. Com a pesquisa, segundo as autoras, foi possível não somente compreender como o racismo e o machismo obstaculizaram as trajetórias das mulheres, mas conhecer os ambientes educativos que, para além do ambiente escolar, contribuíram para a formação dessas mulheres quilombolas.

No artigo Jovens negras periféricas: afloradas interseccionalidades de raça e gênero, as autoras articulam a discussão da interseccionalidade de raça e gênero com o contexto socioeconômico, trazendo para isso as experiências de um grupo de jovens negras trabalhadoras de Belo Horizonte.

A pesquisadora do artigo Em legítima defesa: a escrita feminina negra como enfrentamento e transgressão reflete sobre o racismo e machismo estruturais e seus efeitos no que diz respeito à invisibilização da intelectualidade de mulheres negras, problematizando estereótipos criados em nossa sociedade. Defende a produção escrita de mulheres negras como forma de resistência e de luta.

No quarto artigo do dossiê, O problema da introdução das línguas nacionais no sistema educacional formal do Benim: forças e restrições, os autores debruçam-se sobre o Sistema de Educação Formal daquele país, tendo como objetivo demonstrar "[...] a relevância da introdução das línguas nacionais". A pesquisa, realizada com funcionários do Ministério da Educação; funcionários da Direção de Promoção de Idiomas; familiares de alunos e técnicos de recursos humanos discute a relação das línguas nacionais com a cultura, e confirma que "[...] a introdução de idiomas 
nacionais no sistema educacional beninense contribui para o desenvolvimento e a escolaridade de crianças, com bons resultados acadêmicos".

No artigo Pedagogia da circularidade: fundamentos de ensino inspirados no Unzó ia Kisimbi ria Maz̧a Nrambi" apresenta-se uma pesquisa que "[...] reflete sobre os processos de ensino e aprendizagem inspirados no conhecimento tradicional do Candomblé Congo-Angola, ancorado na filosofia Bantu, em sua visão de mundo e noção de sociedade." Para tanto, o autor discute experiências de ensinar / aprender em um terreiro de Simões Filho, município do estado da Bahia.

$\mathrm{O}$ artigo Educação das relações étnico-raciais: em foco as vivências em uma turma de crianças de quatro anos de idade trata da presença da história e cultura afro-brasileira nas práticas pedagógicas da educação infantil, em especial, de crianças de 4 anos de idade em instituição que utiliza material didático do tipo apostilas. A análise do uso desse material produzido por sistemas privados, adotado por sistemas públicos para essa etapa da educação básica põe em questão a ação docente na escolha de atividades que melhor se adequem aos grupos de crianças, em especial bebês, e compromete a inserção nas interações entre as crianças e suas experiências nas discussões sobre o pertencimento étnico-racial.

O texto Diálogos possiveis entre escolas e terreiros - estratégias de luta contra o racismo traz à tona a presença de crianças de Terreiros e os conhecimentos produzidos por elas e com elas na relação com as heranças ancestrais, em particular, de meninas que exercem o papel de Makotas em seus Terreiros, lugar de prestígio e importância no campo religioso, produzindo ruptura no adultocentrismo presente na sociedade brasileira. Destaca, ainda, os tensionamentos entre racismo religioso, espaços educacionais, respeito às singularidades inerentes a distintas religiões e efetivação de normativas no campo da educação que obrigam que instituições protejam crianças contra o racismo. A análise se faz tendo como referência os estudos decoloniais e ressalta a resistência que tem sido empreendida por pessoas praticantes de religiões de matriz africana na construção de uma educação antirracista.

No artigo Formação de professores e racismo: para onde vamos? há reapresentação do tema do racismo presente na formação de professores; para tanto, destaca-se a correlação entre esse fenômeno e aspectos de raça e gênero que afetam a discussão sobre o tema em processos formativos. Enfatiza que a escola deve cumprir seu papel no sentido de romper com a indiferença de muitos professores quanto à problemática do combate ao racismo em espaços escolares.

O texto Encruzilhada de saberes em tempos de cólera: curriculo decolonial e pedagogias de escrevivência estabelece a intrínseca relação entre a organização curricular de uma universidade pública federal, a presença de uma professora negra e sua experiência pautada no conceito de escrevivência de Conceição Evaristo, e de referenciais na perspectiva decolonial, o que possibilitou o exercício de uma ação docente "[...] comprometida com perspectiva epistemológica antirracista, interdisciplinar, interprofissional, intercultural e interepistêmica".

$\mathrm{O}$ artigo Afrocentricidade e pensamento decolonial: perspectivas epistemológicas para pesquisas sobre relações étnico-raciais problematiza esses dois referentes teóricos que ganharam maior impulso em pesquisas em educação após a aprovação da Lei n. 10.639/2003. Tal afirmação se ampara em estudo realizado a partir de trabalhos apresentados nos últimos dez anos no GT 21 da ANPEd e do Congresso Brasileiro de Pesquisadores/as Negros/as (COPENE) cujos títulos mencionaram os termos afrocentrada e decolonial. De acordo com os resultados, as/os autoras/es concluem que é "[...] possível reconhecer as contribuições de ambas as perspectivas teóricas à medida que pensam possibilidades, saberes, epistemologias, formas de conceber o mundo e a vida que não unicamente pela ótica eurocêntrica". 
O artigo Danças em Terreiros: educação dos corpos para as giras na Quimbanda aborda as relações entre pedagogias, ensino dos movimentos e danças de entidades espirituais do universo religioso em terreiros de Quimbanda, na cidade do Rio Grande, no Rio Grande do Sul. A partir das narrativas de homens e mulheres dos terreiros aprendemos e revivemos, no desenvolvimento do artigo, como as danças expressam modos de contar e recontar mitologias das entidades bem como rotinas dos terreiros. Com enfoque no arquétipo de exus e pombagiras são contextualizados os significados dos gestuais que simbolizam alegrias, identidades, batalhas, insatisfação de entidades, representando histórias e enredos que intercambiam mundos entre os deles(as) e o nosso, segundo os partícipes da pesquisa. A Quimbanda revela-se, assim, um espaço singular para a compreensão de expressões plurais de corporeidade, identidade e para um processo denominado de pedagogização dos sujeitos pertencentes a esses espaços que, no caso desse estudo, foi focalizado e percebido, especificamente, pela educação dos corpos.

O artigo Maracatu rural na proposta pedagógica curricular da educação infantil de Nazaré da Mata Pernambuco analisa como políticas curriculares de educação infantil do município de Nazaré da Mata em Pernambuco atendem orientações de legislações voltadas à educação das relações étnico-raciais. A partir de um trabalho de análise documental e da realização de entrevistas com gestoras/es e professoras/es notou-se um processo de implementação ainda inicial e restrito às datas comemorativas, a despeito da menção ao maracatu nos documentos que orientam políticas para a educação infantil. Considerando a importância do maracatu rural na cidade incluída a participação das crianças em toda a região da Mata Norte de Pernambuco, o artigo dedica-se em um segundo momento a detalhar de que forma, durante a pesquisa, foram construídas propostas de trabalho com o maracatu, nos eixos já existentes nos documentos oficiais como, por exemplo, a Base Nacional Comum Curricular. A pesquisa culminou na proposição de encontros formativos em parceria com a Universidade Federal de Pernambuco (UFPE).

No artigo Socialização étnico-racial de crianças na creche de uma comunidade remanescente de quilombos analisam-se interações construídas entre crianças negras e não negras remanescentes de quilombolas que frequentam a creche da própria comunidade, localizada na região metropolitana de Fortaleza, no Ceará. Com o objetivo de estabelecer diálogo com os estudos sobre processos de socialização e de construção da identidade étnico-racial na infância, o estudo definiu o contexto não urbano para a realização da pesquisa de campo, que contou com a realização de observações e anotações em diários de campo. Os resultados indicam que as características fenotípicas das crianças não foram determinantes nas interações entre as crianças.

$\mathrm{O}$ artigo intitulado Autodeclaração racial e desdobramentos educacionais na Escola Estadual General Aževedo Costa dedicou-se à análise de processos de reconhecimento de autodeclaração de cor e/ou raça de estudantes do ensino médio de uma escola pública de Macapá, no Amapá. Por meio de entrevistas, registros e anotações de atividades de campo constatou-se que a autodeclaração racial é configurada de maneira complexa pelos discentes, ainda permeada de tensões que indicam a necessidade de aprofundar a implementação da temática em processos formativos de jovens.

No artigo Evasão e permanência de cotistas e não cotistas no ensino médio volta-se o foco para uma análise do índice de evasão e permanência anual dos estudantes cotistas raciais em comparação aos ingressantes por ampla concorrência em cursos técnicos integrados de nível médio, no período de 2013 a 2018, em instituição federal localizada no Sul de Minas Gerais. Os resultados, sintetizados a partir da análise de relatórios e formulários disponibilizados pela Coordenação de Registro Escolar e Controle Acadêmico, indicam que há variação da taxa de evasão e permanência escolar nos três cursos técnicos estudados. Evidenciam também que o índice de permanência de estudantes cotistas raciais é maior, comparado aos discentes oriundos de ampla concorrência, e que há menor índice de evasão entre mulheres em todos os períodos letivos. Em 
instrumento complementar e qualitativo, analisaram-se os principais motivos para a não conclusão do curso, destacando-se entre as principais causas de evasão escolar: a dificuldade de aprendizagem; a falta de tempo em se dedicar aos estudos; seguidos do motivo de já haverem sido reprovados anteriormente na instituição. Por fim, destaca-se a necessidade de estudos sistemáticos sobre evasão e permanência ocorrerem de forma concomitante a mudanças institucionais que considerem políticas de ação afirmativa na educação técnica, para além do acesso.

No texto Representações sociais de docentes sobre relações étnico-raciais na educação básica na Amarônia estão reunidos resultados do Projeto de Extensão da Universidade Federal do Pará em Bragança, que tem oportunizado ações de formação continuada em relações étnico-raciais para professores da educação básica. Inspirado em aporte metodológico qualitativo com foco na análise das representações sociais foi observado o impacto da ação extensionista na transformação de práticas pedagógicas relacionadas ao tema, que tem oportunizado a professores processos de ressignificação de conceitos acerca da diversidade étnica e de práticas pedagógicas voltadas para a promoção da igualdade étnico-racial. A pesquisa compreendeu também um levantamento de percepções iniciais de professores sobre a temática, que demonstrou a ausência do tema na formação inicial desses professores e o pouco contato dos profissionais com a legislação e diretrizes pertinentes à temática.

O texto Trincheiras culturais, a Lei n. 10.639/2003 e a Baixada Fluminense: um estudo de caso parte da centralidade e protagonismo dos Núcleos de Estudos Afro-Brasileiros e/ou grupos correlatos em instituições de ensino superior do país, em favor da implementação de leis e diretrizes que regulamentam a educação das relações étnico-raciais. Ao resgatar e historicizar ações de formação docente, promovidas pelo Laboratório de Estudos Afro-brasileiros (LEAFRO) - Núcleo de Estudos Afro-brasileiros e Indígenas (NEABI) da Universidade Federal Rural do Rio de Janeiro, fortalece-se a compreensão de que uma educação de bases antirracistas implica a crítica ao mito da democracia racial, a compreensão dos mecanismos de exclusão que recaem sobre a população negra, apontando na direção das possibilidades de se interferir em processos de qualificação docente na perspectiva da Lei n. 10.639/2003, produzindo conhecimentos instituintes de princípios que valorizem a educação das relações étnico-raciais.

$\mathrm{O}$ artigo intitulado $A$ atuaşão do movimento negro $e$ as questões raciais no curso de Pedagogia da UFSC dedica-se à análise do processo de institucionalização da educação das relações étnicoraciais no currículo do curso de Pedagogia da Universidade Federal de Santa Catarina, com foco na atuação do Núcleo de Estudos Negros (NEN), organização social vinculada ao movimento negro. A partir da análise de documentos curriculares, manifestos, atas e publicações do curso e do NEN, bem como de documentos nacionais que orientam a educação das relações étnicoraciais e a formação docente, reconstrói-se no artigo a trajetória do processo de institucionalização do debate étnico-racial no curso de Pedagogia, mobilizado como mote para registrar a importância histórica do movimento negro e das lutas antirracistas para a democratização da escola, da universidade e da sociedade brasileira.

O artigo Homens negros, futebol e memórias coletivas em Mato Grosso analisa os significados que ex-jogadores atuantes entre os anos 1950 a 1970 atribuíram às suas vivências como homens negros no futebol, e como elas se articulam com as relações étnico-raciais. Por meio da história oral entramos em contato com dez entrevistados que relatam as dificuldades de estrutura à época, mas também o orgulho e a satisfação de ocuparem esses postos. Esses homens, porém, destacam o racismo presente que se metamorfoseava em "rivalidades" do futebol. Cada um dos depoentes percorre suas memórias apresentando rupturas com a subalternidade atribuída a negros por meio de suas atitudes no futebol. 
O Centro Afrocarioca de Cinema como espaço de educabilidade decolonial é um artigo em que autor apresenta a produção cinematográfica negra realizada desde os anos 1970, demarcando esse movimento como parte intrínseca da luta antirracista e estabelecendo articulações entre raça e cultura. Apresentando a produção realizada no Centro como fomento ao trabalho com a educação para as relações étnico-raciais, o autor traz a marca de Zózimo Bulbul, um dos fundadores e um dos mais importantes interlocutores do cinema negro brasileiro. Bulbul é colocado em diálogo com Joel Zito, outro nome relevante para a cinematografia com assinatura negra, o que nos aproxima da sétima arte e de como a ação negra dialoga com a pedagogia decolonial.

Em Cinema negro na educação antirracista: uma possibilidade de reeducação do olhar situa-se o conceito de Cinema negro, passando pelo Cinema novo e chegando aos cineastas, manifestos e produção fílmica da contemporaneidade que destaca a representação do negro do modo reivindicado pelo movimento negro. Alia-se a essa discussão o papel fundamental de reeducação do olhar e de possibilidades de novas representações do negro desenvolvidas no Centro Afrocarioca, demarcando a contribuição da cultura visual na constituição de uma educação antirracista.

O artigo Implementação da Lei n. 11.645/2008: uma experiência na formação de professores diz respeito ao trabalho da história e culturas indígenas em escolas de Campo Grande, no Mato Grosso do Sul, tema ainda pouco debatido quando se trata de educação para as relações étnicoraciais. Reflete sobre o tema a partir da experiência desenvolvida pelas autoras em cursos de formação de professoras orientadas por perspectivas pós-coloniais e decoloniais. Chama a atenção de que, em primeiro momento, a legislação foi compreendida pelos profissionais da educação como normativa destinada às escolas situadas em comunidades indígenas ou em instituições com presença de indígenas. Trabalhando também a partir de narrativas de professores quanto a estereótipos sobre povos indígenas ainda presentes nos imaginários desses educadores, discute a necessidade de desnaturalização das percepções sobre esses povos, construídas pela colonização e que perduram na contemporaneidade, impedindo compreender os múltiplos saberes que constituem os brasileiros.

No artigo Contribuições dos estudos críticos sobre relações étnico-raciais ao campo da educação os autores objetivam "[...] explorar conceitos e pesquisas oriundos dos estudos críticos sobre relações étnico-raciais (em especial das ciências sociais) e verificar como eles podem ser mobilizados no campo da educação", concluindo que conceitos, tais como racismo institucional e racialização, por exemplo, são relevantes para pensar questões étnico-raciais nesse campo.

No artigo Significações sobre a ERER: uma análise de publicações em periódicos da Educação (20152019) as autoras, a partir de levantamento de artigos sobre educação realizado no período de 2015 a 2019 destacam: a) temáticas recorrentes na área; b) possibilidades de temas para a realização de novas investigações; e c) recomendações da produção para a implementação da Lei n. 10.639/2003. As autoras concluem que "A problematização dessas temáticas nunca esteve tão viva e proeminente nos debates e estudos em todos os âmbitos da formação inicial e continuada de professores. Os seus reflexos na escola são cada vez mais evidentes e, por conseguinte, nas trajetórias escolares de crianças e adolescentes negros e negras".

A seção temática de Teias aqui apresentada é uma contribuição significativa para o campo dos estudos de raça e cultura, nos aproximando de múltiplas análises que percorrem o campo e que, seguramente, indicam outros caminhos a serem trilhados nas pesquisas que virão, inspiradas nas leituras dos artigos aqui reunidos. Como confirma a epígrafe com a qual iniciamos o texto, somos nós mesmas contando nossas próprias histórias. 


\section{REFERÊNCIAS}

CARNEIRO, Aparecida Sueli; FISCHMANN, Roseli. A construção do outro como não-ser como fundamento do ser. São Paulo: Editora da Universidade de São Paulo, 2005.

KILOMBA, Grada. Memórias da plantação: episódios de racismo cotidiano. Rio de Janeiro: Cobogó, 2019.

QUIJANO, Aníbal. Colonialidade do poder, eurocentrismo e América Latina. In: LANDER, Edgardo (org.). A colonialidade do saber, eurocentrismo e ciências sociais. Perspectivas latino-americanas. Buenos Aires: Clacso, Colección Sur Sur, 2005.

\section{Informações das autoras}

Lucimar Rosa Dias

Universidade Federal do Paraná

E-mail: lucimardias1966@gmail.com

ORCID: http://orcid.org/0000-0003-1334-5692

Link Lattes: http://lattes.cnpq.br/3476684741346049

Mailsa Carla Pinto Passos

Universidade do Estado do Rio de Janeiro

E-mail:mailsappassos@gmail.com

ORCID: http://orcid.org/0000-0003-1204-4505

Link Lattes: http://lattes.cnpq.br/9865045321306211

Tatiane Cosentino Rodrigues

Universidade Federal de São Carlos

E-mail: tatiane.cosentino@gmail.com

ORCID: https://orcid.org/0000-0002-4402-2805

Link Lattes: http://lattes.cnpq.br/8361431964064731 